\title{
Cellular Approaches to Tissue-Engineering of Skin: A Review
}

\author{
Wei Long $\mathrm{Ng}^{1,2}$, Wai Yee Yeong ${ }^{2}$ and May Win Naing ${ }^{1^{*}}$ \\ ${ }^{1}$ Singapore Institute of Manufacturing Technology, Agency for Science, Technology and Research, 71 Nanyang Drive, Singapore \\ 2Singapore Centre for 3D Printing (SC3DP), School of Mechanical and Aerospace Engineering, Nanyang Technological University (NTU), 50 Nanyang Drive, Singapore \\ *Corresponding author: May Win Naing, Singapore Institute of Manufacturing Technology, Agency for Science, Technology and Research, 71 Nanyang Drive, \\ Singapore, Tel: +65 6793 2193; E-mail:winnaingm@SIMTech.a-star.edu.sg
}

Rec date: Jan 29, 2015; Acc date: Mar19, 2015; Pub date: Mar 23, 2015

Copyright: () 2015 May Win Naing. This is an open-access article distributed under the terms of the Creative Commons Attribution License, which permits unrestricted use, distribution, and reproduction in any medium, provided the original author and source are credited.

\begin{abstract}
The human skin is a complex organ consisting of multiple skin cells that work together to complement each other and provide essential functions such as skin barrier function, skin homeostasis and protection against the harmful ultraviolet radiation. Understanding the roles and paracrine signaling of different skin cells plus the influence of external stimuli on them are crucial towards the design of tissue-engineered skin constructs as these factors regulate the cellular behavior such as cell proliferation, migration and differentiation. Hence, an in-depth understanding of the knowledge on the epithelial-mesenchymal interactions would be valuable towards the design of a tissue-engineered skin construct.
\end{abstract}

Keywords: Skin; Keratinocytes; Melanocytes; Fibroblasts; Stem cells; Tissue Engineering

\section{Introduction}

Human skin, which is the body's largest organ, not only protects us against a plethora of deleterious stressors such as chemical, mechanical and biological insults but also plays a critical role in maintaining the body homeostasis. Wounds are breaches in skin's structure that compromise the skin barrier functions and they can be classified into different categories such as I) epidermal, II) superficial partialthickness, III) deep partial-thickness or IV) full-thickness wounds based on the depth of injury [1]. In severe cases such as chronic ulcers or extensive burns, the wounds extend deep into the dermis region (full-thickness wounds) and they do not close without intervention. Any full-thickness wound larger than $1 \mathrm{~cm}$ in diameter requires the use of a skin graft for proper healing and the current "gold standard" treatment is to apply split-thickness grafts onto the wound site [2]. In the United States, an estimated US \$25 billion is spent on wound treatment annually and this healthcare burden is expected to snowball drastically due to escalating healthcare costs and increasing aging population worldwide [3].

Although the limited availability of suitable skin grafts poses a major challenge, development of tissue-engineered skin substitutes can help to alleviate this problem [4]. At present, tissue-engineered skin substitutes are already a reality due to extensive research in cell biology, wound healing mechanisms and breakthrough in cell culture techniques $[5,6]$. The advent of skin tissue engineering has brought about a paradigm shift in wound management from the use of passive wound dressings to bioactive skin regeneration scaffolds [7]. Tissueengineered skin constructs comprising of living cells, biomaterials and biochemical signals aim to expedite wound healing by stimulating the innate capability of the skin for self-regeneration. The gradual understanding of wound healing mechanisms has invoked the development of bioactive skin regeneration scaffolds that promote skin rejuvenation via the incorporation of different skin cells within tissue-engineered scaffolds. As the skin cells themselves are the primary sources of various extracellular matrix (ECM) molecules that stimulate and coordinate tissue repair, it is important to understand the roles of these cells within the native skin. In this review, the roles of different skin cells and their paracrine signaling are highlighted. In addition, the current progress of tissue-engineered skin substitutes and the potential use of stem cell technology for skin tissue engineering will be discussed.

\section{Cellular Components of Skin}

The skin cells found in tissue-engineered skin can be categorized into autologous (from the patient's own cells) or allogeneic (from genetically non-identical donors) cell source. Both autologous and allogeneic skin cells have been used in commercially available skin substitutes and they help to initiate wound healing process [8]. The advantages of utilizing an autologous cell source include the comparatively low requirement for safety testing and a lower risk of immunological rejection by the patients, while the limitations include lengthy cultivation time ( $\sim 15$ to 30 days) and high manufacturing costs arising from having to use separate, independent tissue culture suites. In contrast, allogeneic cell source has the advantages of immediate clinical applications to injured skin and the use of common tissue culture facility for each cell type allows the economies of scale and straightforward logistics. The limitations include more stringent safety-testing, potential risk of immunological rejection and disease transmission. In the following section, the roles of different skin cells in their respective regions and the influence of external factors on cell migration, proliferation and differentiation will be presented and highlighted.

\section{Keratinocytes}

Keratinocytes found in epidermis (the outermost layer of the skin) form an impermeable barrier to pathogens and play an important role in cell signaling within the extracellular matrix. The epidermis measures about $0.2 \mathrm{~mm}$ thick and epidermal keratinocytes with different degrees of differentiation are arranged into 4 layers within the epidermis as depicted in Figure 1 (namely stratum corneum, 
stratum granulosum, stratumspinosum and stratum basale). The outermost stratum corneum is a cornified layer of 15-30 sheets of terminally-differentiated keratinocytes (corneocytes). The next inner layer (stratum granulosum) consists of 3-5 sheets of granular layer of non-dividing keratinocytes, which flatten as the dividing cells below progressively push them to the skin surface. The following layer (stratum spinosum) consists of 8-10 sheets of keratinocytes with limited capacity for cell division. The basal or dividing layer of the epidermis (stratum basale) houses the differentiating keratinocytes and keratinocyte stem cells. Every keratinocyte in the basal layer would eventually mature and differentiate into corneocyte, followed by organizing into "bricks-and-mortar" arrays that provide the important skin barrier function [9].

Autologous keratinocytes are required for the development of a permanent skin substitute as allogeneic keratinocytes are usually rejected by the host [10]. The major challenge encountered was the lengthy cultivation period for autologous keratinocytes from skin biopsies prior to obtaining sufficient amount of keratinocytes for clinical application. Strategies that were proposed to alleviate this problem include the use of low calcium medium to enhance the proliferation rate of keratinocytes, the use of sub-confluent keratinocytes on functionalized plasma treated surfaces or fibrin glue and chimeric composition of keratinocytes (a mixture of allogeneic and autologous keratinocytes) [11-17]. Interestingly, allogeneic neonatal foreskin-derived keratinocytes do not elicit immune rejection due to undeveloped human leukocyte antigen (HLA) tissue markers and they also demonstrate high proliferation and differentiation capabilities $[18,19]$. The proliferation of keratinocytes is highly dependent on the epithelial-mesenchymal interactions [10]; the keratinocytes cease to proliferate after 1 week and differentiate into discontinuous epithelium in the absence of fibroblasts.

Upon reaching confluency, these proliferating keratinocytes would undergo a sequential differentiation process which is regulated by a calcium gradient across the epidermal region to form fully stratified keratinocyte layers that provide the epidermal barrier function [20]. In another study, both calcium and vitamin D were shown to activate the phospholipase C (PLC) and protein kinase C (PKC) signaling pathways that are involved in the regulation of keratinocyte differentiation [21]. A recent study also highlighted the synergetic effect of multifactorial external stimuli (calcium, confluence, serum and lower incubation temperature) on optimal differentiation of in vitro keratinocytes [22]. The proliferation and differentiation of the keratinocytes are regulated by a variety of biological factors; the change in protein phosphorylation is one of the major mechanisms that alter the keratinocyte's response to extracellular signals. This protein phosphorylation process involves the binding of ligands to receptors which subsequently leads to the activation of several transduction pathways in keratinocytes. These signal transduction pathways include protein tyrosine kinases (PTK), protein kinase A (PKA), protein kinase $\mathrm{C}$ (PKC), mitogen-activated protein kinase (MAPK), casein kinase II, phospholipases and cytokine receptor superfamily [23]. The activation of the tyrosine kinase activities and tyrosine phosphorylation are required for keratinocyte differentiation; which is closely associated with epithelial growth factor receptor (EGFR), calcium concentration $\left(\mathrm{Ca}^{2+}\right)$ and 12-0tetradecanoylphorbol-13-acetate (TPA). It was also shown that PKC activation is essential for keratinocyte terminal differentiation [24] and this activation is regulated by $\mathrm{Ca}^{2+}$, diacylglycerol (DAG) or phorbol ester. PKC is an important transduction pathway that regulates the sequential differentiation of keratinocytes from the spinous to granular region in the epidermal skin. Keratinocytes in a reduced $\mathrm{Ca}^{2+}$ concentration $(0.05 \mathrm{mM})$ demonstrates a basal-cell like morphology, whereas keratinocytes cultured in higher $\mathrm{Ca}^{2+}$ concentration $(0.12$ $\mathrm{mM}$ ) leads to sequential induction of early differentiation markers (in the spinous cells) such as keratins 1 (K1) and 10 (K10) and late markers (in the granular cells) that include involucrin, profilaggrin and loricrin [20]. More comprehensive reviews on the signal transduction pathways in keratinocytes were already covered $[23,25,26]$.

The substrate stiffness also plays a critical role in regulating the proliferation, migration and differentiation of the keratinocytes; a stiffer surface is preferred for keratinocyte migration and proliferation, whereas a softer surface is favorable for keratinocyte differentiation [27]. Furthermore, the widely-accepted practice of culturing confluent keratinocytes at the air-liquid interface is another critical step in the formation of a fully-stratified epidermal layer [28,29]. Understanding these mechanisms that regulate the proliferation and differentiation process of keratinocytes will aid in the development of techniques and procedures for accelerated maturation of a fully functional epidermal layer.

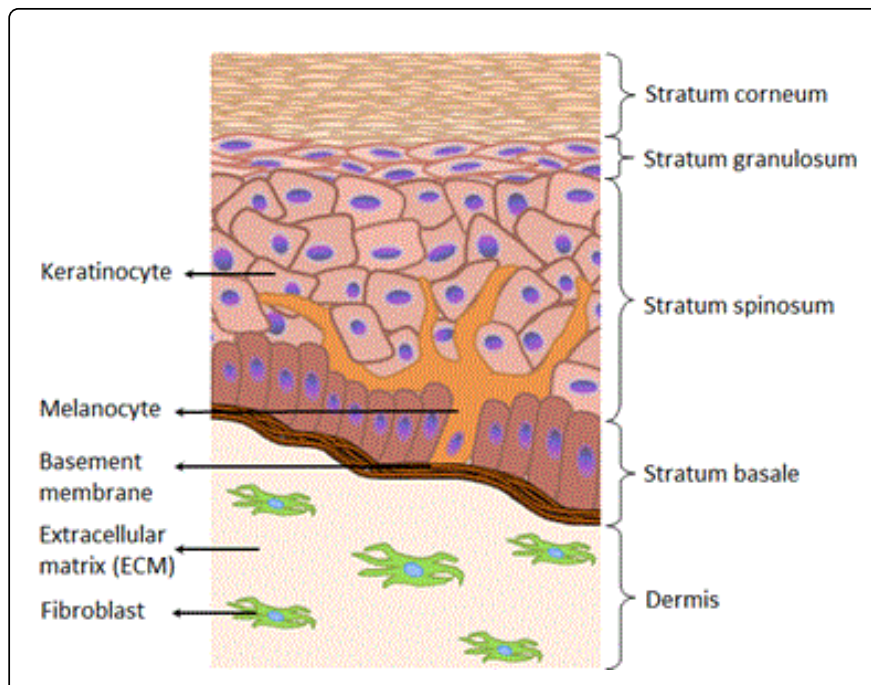

Figure 1: Schematic drawing of human skin

\section{Melanocytes}

Melanocytes found on the basement membrane at the epidermaldermal junction, synthesize the pigment melanin which provides our distinct skin colour and protects us against the ultraviolet radiation (UV-R). The melanin are synthesized and stored within melanosomes, which are then transferred to the overlying suprabasal keratinocytes via elongated dendrites. These melanins can be categorized into eumelanin (black to brown colour), pheomelanin (yellow to reddishbrown colour), neuromelanin (brown/black colour) and mixed melanin pigment (contains both eu- and pheonomelanin) [30]. The variation in skin colour is attributed to the density, size and distribution of melanosomes to the cluster of surrounding keratinocytes. Although every individual has a distinctive skin colour, the melanocyte density in a specified area is identical for all skin types [31]. The ratio of epidermal melanocytes to basal keratinocytes in the human skin is approximately 1:20 and it is imperative to note that a minimum density of $1.0 \times 10^{4}$ melanocytes $/ \mathrm{cm}^{2}$ is required to restore 
the skin pigmentation completely [32]. The main components of a basement membrane (BM) consist of collagen type IV, collagen VII and laminins and the presence of a basement membrane is essential for the positional orientation of the melanocytes [33]. In the absence of BM, these melanocytes migrate to the superficial keratinocyte layers and undergo spontaneous pigmentation. In an elegant study, it was demonstrated that the dynamic epithelial-mesenchymal interactions required for basement membrane formation are predominantly regulated by diffusible factors without the need for direct keratinocytefibroblast contact [34].

The epidermal melanin unit (EMU) is a functional complex unit found within the epidermis that consists of both keratinocytes and melanocytes. Once melanosomes are transferred to the keratinocytes, the melanin granules accumulate above the nuclei and absorb the harmful UV-R. The keratinocyte-melanocyte complex reacts spontaneously to a wide range of external stimuli in both autocrine and paracrine signaling [35]. Upon stimulation, increased expression of proopiomelanocortin (POMC, precursor of melanocyte-stimulating hormone) and its receptor melanocortin 1 receptor (MC1-R) by melanocytes was observed. Furthermore, production of keratinocytederived factors such as adrenocorticotropic hormone (ACTH), alphamelanocyte stimulating hormone ( $\alpha-\mathrm{MSH})$, basic fibroblast growth factor (bFGF), nerve growth factor (NGF) and endothelins was detected. Fibroblasts also respond to UV-R by producing melanogenic factors such as hepatocyte growth factor (HGF), stem cell factor (SCF) and bFGF.

One of the main challenges in cultivation of melanocytes is due to drastic reduction in number of melanocytes after serial sub-cultivation and cryopreservation [36]. Conventionally, melanocytes are isolated from the primary culture consisting of both keratinocytes and melanocytes. This leads to low initial density and subsequently, low proliferative capacity in the first passage. In a recent study, the melanocytes were co-cultured with keratinocytes present in the primary culture until sufficient melanocytes are obtained [37] and the presence of keratinocyte-derived growth factors enhance the differentiation, migration and proliferation of the melanocytes. It was also reported that phospholipase A2, a component of bee venom, helps to stimulate melanocyte dendricity and pigmentation [38]. Extensive research was conducted to induce the differentiation of different stem cells into melanocytes [39-42] and this provides alternative sources of melanocytes which could overcome the above limitation.

Recent works on reconstruction of tissue-engineered skin containing melanocytes clearly emphasize the poor reliability of animal models [43]. Reconstructed pigmented skin substitutes transplanted on the full-thickness defects created on the back of the nude rats showed darker pigmentation as compared to the donor melanocytes [44]. This observation is corroborated by an earlier study [45] that murine fibroblasts were shown to secret more soluble factors that increase the pigmentation. Markedly, it was shown in another study that the skin colour of the reconstructed pigmented skin transplanted onto full-thickness defects on the backs of nu/nu rats was similar to the donor skin, independent of the melanocyte to keratinocyte ratio used [46]. The surgical steel rings that were sutured to the full-thickness skin defects prevent wound closure with the surrounding rat skin; this might negate the influence of murine fibroblast on the skin pigmentation [33]. To the best of our knowledge, no work on the use of allogeneic melanocytes that closely matches the patient's skin colour for skin repigmentation has been reported.

\section{Fibroblasts}

Fibroblasts residing in the dermal region produce collagen, growth factors, glycosaminoglycans (GAGs), and fibronectin to initiate wound healing process. The dermis is predominantly extracellular matrix with low fibroblast density [47] and this dermal region can be further divided into an upper 'papillary' and a lower 'reticular' region. The papillary dermis is characterized by thin, randomly orientated collagen fiber bundles (with a high ratio of type III to type I collagen) that are arranged into ridge-like structures, while the reticular dermis consists of numerous thick, orderly-orientated fiber bundles (low ratio of type III to type I collagen) as illustrated in Figure 2. The dermal fibroblasts are heterogeneous and the papillary and reticular fibroblasts are known as superficial and deep fibroblasts respectively [48]. Recent studies on evaluation of the fibroblast heterogeneity on wound healing have shown that incorporation of superficial dermal fibroblasts within cultured skin substitutes demonstrated reduced hypertrophic scarring and improved basement membrane and epidermal barrier formation $[49,50]$.

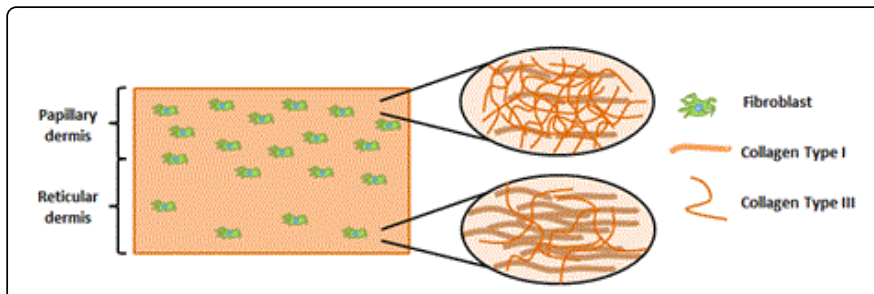

Figure 2: Schematic drawing of the collagen fiber distribution within the dermal region

A study on cell adaptation to a physiologically relevant ECM with varying viscoelastic properties demonstrates contrasting effects, whereby the fibroblasts migrate faster $(0.81 \mu \mathrm{m} / \mathrm{min})$ on softer substrates $(95 \mathrm{~Pa})$ while proliferating preferentially on the stiffer substrates $(4270 \mathrm{~Pa})$ [51]. Notably, the proliferation of fibroblasts demonstrated high dependency on the substrate hardness with a dimensionality-specific response [52]. In contrast to higher proliferation rate on a $2 \mathrm{D}$ microenvironment with increasing substrate stiffness, the fibroblasts demonstrated slower proliferation rate within a 3D microenvironment with increasing substrate stiffness. Although the knowledge on fibroblast biology within a $3 \mathrm{D}$ microenvironment is integral towards our understanding of the cell-matrix interactions and development of improved skin substitutes; it is beyond the scope of this review. Detailed reviews on the fibroblast mechanics and biology within $3 \mathrm{D}$ collagen matrices could be found elsewhere [53,54]. Other factors that affect the fibroblast proliferation include passage number, donor's age and fibroblast phenotype [55]. Furthermore, the presence of vitamin C and antioxidant (coenzyme Q10) were shown to increase migration and proliferation of fibroblasts [55].

In contrast to allogeneic keratinocytes, numerous reports advocated the hypothesis that allogeneic fibroblasts can be tolerated by the host and long-term grafting of these fibroblasts for up to 2 months was demonstrated [10,56-60]. Notably, the allogeneic neonatal fibroblasts are more responsive to mitogens as compared to allogeneic adult fibroblasts [61]; they migrate faster and have a shorter cell population doubling time [62]. The allogeneic fibroblasts in the cultured skin substitutes are gradually replaced by the host cells over time [21]; hence the use of autologous fibroblasts in dermal substitutes is required for permanent engraftment and was shown to result in better 
restoration and minimal scar formation as compared to allogeneic dermal substitute $[63,64]$.

The feeder cell-culture system is an exemplar which clearly depicts the importance of epithelial-mesenchymal interactions. The keratinocyte-derived interleukin-1 (IL-1) stimulate the fibroblasts to synthesize and secrete growth factors and cytokines such as keratinocyte growth factor (KGF) / fibroblast growth factor -7 (FGF7), interleukin 6 (IL-6), and granulocyte macrophage colony-stimulating factor (GM-CSF) [65], which in turn regulates keratinocyte proliferation and differentiation in the keratinocyte-fibroblast cocultures [66]. This elucidates the existence of a double paracrine loop and highlights the significance of epithelial-mesenchymal interactions. Nevertheless, it is important to note that the presence of fibroblasts in the tissue-engineered skin induced a reduction in melanocyte pigmentation as compared to tissue constructs without fibroblasts [45] and this observation is corroborated by another study which highlights that the presence of fibroblast-secreted proteins, Dickkopf 1 (DKK1), suppress the melanocyte function and proliferation [67]. As such, it is desirable to have a low fibroblast density within the tissue-engineered skin constructs which closely mimics the native dermal region.

\section{Current Progress of Tissue-engineered Skin Substitutes}

The demand for improved healing outcomes has invoked the development of skin substitutes that actively promote wound regeneration. Over the last three decades, several tissue-engineered skin substitutes have been developed and they have emerged as important therapeutic products for treatment of chronic wounds or extensive burns. These novel skin substitutes can be classified into epidermal, dermal and epidermal-dermal (composite) tissueengineered constructs. Nevertheless, some of the limitations include more stringent safety-testing, potential risk of immunological rejection and disease transmission. In the subsequent sections, the types of skin substitutes and their respective roles will be briefly covered.

\section{Epidermal Skin Substitutes}

Epidermal skin substitutes containing autologous keratinocytes are often cultivated on top of irradiated murine fibroblast feeder layer. These autologous keratinocytes from patient's skin biopsy are usually cultivated and expanded in laboratories over a period of approximately 3 weeks to obtain stratified keratinocyte cell sheets, which are also known as cultured epithelial autografts (CEAs). Over the last three decades, confluent CEAs have been utilized for treatment of extensive burns and temporary wound dressings are required due to the lengthy cultivation period for CEAs. Furthermore, these CEAs (which typically range between 2 to 8 cell layers thick) do not result in satisfactory healing outcomes [68] and meticulous handling of the fragile cell sheets is required.

The use of synthetic carrier templates such as petrolatum gauze backings and silicone membranes provides mechanical support to the fragile cell sheets. Intriguingly, an acid-functionalized silicone membrane was reported to facilitate attachment, proliferation and easy transfer of keratinocytes [69]. However, these carrier templates are non-biodegradable, and as such it is necessary to subsequently remove them from the wound site. The use of natural biomaterials such as fibrin [70,71] and hyaluronic acid [72] as delivery system for cultured keratinocytes provides a suitable microenvironment for migration, proliferation and differentiation of keratinocytes and also improves graft adherence. Furthermore, they can undergo enzymatic degradation in vivo which eliminate the hassle for subsequent removal from the wound sites. The missing dermal component in these skin substitutes often results in unsatisfactory healing outcomes, as the degree of epithelial attachment and scarring is closely dependent on the condition of the underlying dermal wound bed [73]. To improve the clinical outcomes, another type of skin substitute with the dermal component was developed.

\section{Dermal Skin Substitutes}

The biomaterials in dermal skin substitutes not only aid in wound bed preparation, but also provide temporary scaffolds for cell attachment and proliferation [73]. Fibroblasts found in the dermis layer of human skin produce collagen, growth factors, glycosaminoglycans (GAGs), and fibronectin to initiate wound healing. Generally, a two-step process is required for the reconstruction of deep wounds (as shown in Figure 2). The dermal skin substitute is first placed over the wound site for wound bed preparation, followed by the application of an epidermal layer over a well-vascularized dermal layer.

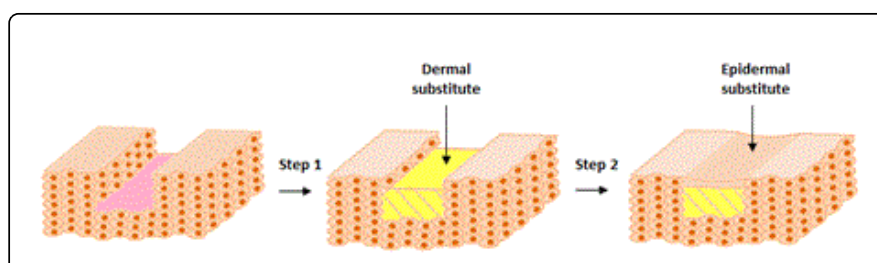

Figure 3: Reconstruction process of a full thickness burn with tissue-engineered skin constructs. A full thickness burn is usually treated via a two-step process by first applying a dermal substitute, followed by an epidermal cover.

These dermal skin substitutes can be further classified into cellseeded scaffolds [74] or acellular scaffolds [75-78]. Most of these commercially available dermal skin substitutes are acellular scaffolds, which mainly function as temporary scaffolds for cellular infiltration and attachment. This could be due to lower manufacturing costs and straightforward logistics and storage [79]. It was highlighted that acellular dermal substitutes could be repopulated by autologous fibroblasts in vivo from day 3 onwards [80]. In contrast, the allogeneic human neonatal fibroblasts present in the cellular dermal skin substitutes die within a few weeks after implantation [10]; hence the cellular dermal skin substitutes only function as a delivery system for temporary production of growth factors and ECM proteins.

\section{Epidermal-Dermal Skin Substitutes}

Epidermal-dermal skin substitutes comprising both epidermal and dermal layers is currently the most sophisticated tissue-engineered skin product that closely resembles the structure of native human skin. The presence of both keratinocytes and fibroblasts within the epidermal-dermal skin substitutes leads to the production of a variety of growth factors and cytokines which expedite wound healing [81-83], highlighting the importance of epithelial-mesenchymal interactions. These epidermal-dermal skin substitutes have been utilized for treatment of chronic wounds and ulcers with higher incidences of wound closure were reported [84].

The epidermal-dermal skin substitutes are around $2.5 \mathrm{~mm}$ thickness on average and delayed vascularization in such thick tissue-engineered 
skin construct remains a critical bottleneck in skin tissue engineering [85]. Integration of a vascularized skin construct with the host vasculature is vital for efficient diffusion of oxygen, nutrients and waste products, as such most cells reside close to the blood capillaries as the oxygen and nutrient diffusion limit is approximately $0.1-0.2 \mathrm{~mm}$ [86]. Different engineering approaches have been proposed to induce the formation of blood vessels in vitro [87]. A combination of cellbased [88], biomaterial-based [89,90] and micro-fabrication approaches [91,92] could possibly alleviate the problem of delayed vascularization. In the cell-based approach, endothelial cell cocultures, growth factor-producing cells or stem/progenitor cells were utilized to accelerate the formation of new blood vessels. Studies have also shown that incorporation of biomaterials such as fibrin [89] or hyaluronic acid [90] within the tissue-engineered constructs can help to improve angiogenesis. In the micro-fabrication approach, miniature channels were fabricated to enhance the oxygen and nutrient diffusion. Detailed reviews on the different vascularization strategies were already covered elsewhere $[88,93,94]$.

Furthermore, the aesthetic outcomes of these skin substitutes remain unsatisfactory [4]. The lack of pigmentation within the skin substitutes leads to the formation of white patches resulting vitiligo, which may result in a negative impact on the patient's social life. A spray-on cell suspension, ReCell ${ }^{\oplus}$, which comprises of non-cultured autologous keratinocytes, melanocytes and fibroblasts, was studied for treatment of vitiligo. In one study, repigmentation time takes approximately 3-5 weeks but clinical results demonstrated good colour match and high extent of repigmentation [95]. Conversely, the results from another study showed that repigmentation of transplanted skin after 4 months is highly dependent on the patient's age, whereby unsatisfactory results (less than 65\%) were obtained for patients above 30 years old [96].

\section{Stem Cell Technology}

Although the use of tissue-engineered skin substitutes have demonstrated some success in the treatment of chronic wounds, current technologies only remain partially effective in mimicking the native human skin (eg. lack of skin appendages, skin pigmentation and extensive network of blood vessels). Extensive stem cell research is being carried out due to their high differentiation and proliferation capacity. The use of stem cells is gaining attention due to their potential to overcome these limitations. In this section, recent studies on the potential use of stem cells in skin tissue engineering will be highlighted and discussed.

\section{Mesenchymal Stem Cells (Mscs)}

Human mesenchymal stem cells (MSCs) are adult stem cells which can be isolated from tissues such as bone marrow $[97,98]$ and adipose tissue $[99,100]$. Bone marrow MSCs (BM-MSCs) were shown to differentiate into multiple skin cell types which aid in wound healing $[97,100]$. It was also demonstrated that BM-MSCs can differentiate into sweat gland cells in vitro [102]. Notably, the BM-MSCs enhance angiogenesis [97,99], which is crucial for wound healing. Although BM-MSCs have many beneficial outcomes, the use of allogeneic MSCs does induce slight immunoreactivity [103].

Human adipose-derived stem cells (ADSCs) could be harvested easily from liposuction of human adipose tissue in a minimally invasive manner, providing an abundant source of autologous cells [104]. An approximately 40-fold yield of MSCs could be obtained from the adipose tissue as compared to the bone marrow [105]. Automatic cell sorters such as Celution ${ }^{\mathrm{TM}}$ system provided a cost-effective and efficient method of isolating and concentrating these stem cells automatically from adipose tissue [106]. A study showed that conditioned medium of ADSCs stimulated collagen synthesis and migration of human dermal fibroblasts (HDFs) [100], thus indicating that ADSCs secreted growth factors which accelerated wound healing. Intriguingly, increased secretion of growth factors such as vascular endothelial growth factors (VEGFs) and basic fibroblast growth factors (bFGFs) is observed under hypoxic conditions [107]. Another study has shown that ADSCs secreted angiogenic cytokines increase neovascularization [108]. Markedly, Chan, et al. have developed vascularized skin constructs from autologous ADSCs, which further differentiated into different mesenchymal cell types by varying the type of hydrogels used in the bilayered construct [99]. Lin, et al. [109] have demonstrated that wound closure rates by ADSC sheets were significantly higher than non-treated control group during the first 18 days. Trottier et al. produced a tri-layered skin substitute using ADSCs, this result elucidated that ADSCs could be used as a potential replacement for fibroblasts in skin reconstruction [110].

\section{Nestin-Positive Stem Cells}

Nestin-positive stem cells are adult stem cells, which can be isolated from the human skin appendages [111-114]. They maintained high proliferation and differentiation capacity during propagation [115]. Markedly, it was demonstrated that nestin-positive stem cells improve wound healing via formation of microvasculature networks [116-118]. Amoh et al. have demonstrated that the incorporation of nestinexpressing hair follicle cells induced the formation of an extensively branched network of blood vessels that anastomose with host vessels in the nude mice models [116].

\section{Amniotic Fluid-Derived Stem Cells}

Human amniotic fluid-derived stem (AFS) cells belong to a new type of stem cells intermediate between embryonic and adult stem cells [119]. Notably, AFS cells can be isolated easily and they demonstrated high proliferation rates without the need of any supportive feeder layer [120]. Furthermore, AFS cells demonstrated high expansion capacity (more than 250 passages) and chromosomal stability [120,121], allowing effective cell banking for off-the-shelf applications. AFS cells do not induce immune rejection [122] and they were shown to secrete cytokines and chemokines essential for accelerated wound healing [123]. Intriguingly, a novel study has demonstrated the ability of AFS cells to support crucial cross-talk between mesenchyme and epithelia needed for epidermal stratification [124]. This finding suggested that AFS cells could be used as an alternative for fibroblasts. A histological study by Skardal et al. [125] elucidated an increased micro-vessel density and capillary diameters in AFS cell-treated wounds as compared to the MSC-treated wounds. Furthermore, proteomic analysis showed that AFS secreted a higher concentration of growth factors than those of MSCs. These results corroborated that bioprinted AFS cells in a mouse model resulted in accelerated healing of large skin wounds. Hence, the use of AFS cells is attractive for skin tissue engineering.

\section{Conclusion}

Over the last three decades, the field of skin tissue engineering has been developing rapidly. This is evident with the development of 
several skin substitutes for treatment of chronic wound and severe burns. They can be categorized into epidermal, dermal and epidermaldermal skin substitutes. The epidermal skin substitutes often result in poor healing outcomes as pre-conditioning of the underlying wound bed is important for epithelial attachment and reduced scarring. This leads to the development of dermal substitutes which function as temporary scaffolds for cellular attachment and infiltration. A twostep reconstruction process is required for full-thickness wound; a dermal substitute helps to condition the wound bed prior to the application of an epidermal substitute on top of the dermal substitute. To eliminate the hassle of two-step reconstruction process, an epidermal-dermal substitute that closely resembles the native skin was developed. The involvement of paracrine signaling from both keratinocytes and fibroblasts accelerate the wound healing process via the secretion of a wide variety of growth factors as highlighted in earlier sections. Despite the advancement in skin tissue engineering, limitations such as delayed vascularization and lack of skin pigmentation remain unsolved.

The purpose of this review is to highlight the paracrine signaling of different skin cells and different external factors that influence the cell migration, proliferation and differentiation. A relatively mature understanding of this knowledge is critical towards the development of improved skin substitutes. The stem cells not only have high proliferation and differentiation capacity but they can also be isolated and propagated easily, hence they could be a potential source of cells for wound healing applications. Nevertheless, it is still important to conduct more preclinical studies to evaluate the potential risks of malignant teratoma formation, amount of cell-dosage administration and long-term adverse effects of these stem cells. These valuable insights would provide significant benefits to patients with chronic wounds or severe burns and the vast potential of skin substitutes has yet to be fully discovered.

\section{Acknowledgement}

The first author would like to thank the scholarship sponsorship by A STAR Graduate Academy.

\section{References}

1. Groeber F, Holeiter M, Hampel M, Hinderer S, Schenke-Layland K (2011) Skin tissue engineering--in vivo and in vitro applications. Adv Drug Deliv Rev 63: 352-366.

2. Papini R (2004) Management of burn injuries of various depths. BM] 329: $158-160$.

3. Sen CK1, Gordillo GM, Roy S, Kirsner R, Lambert L, et al. (2009) Human skin wounds: a major and snowballing threat to public health and the economy. Wound Repair Regen 17: 763-771.

4. MacNeil S (2007) Progress and opportunities for tissue-engineered skin. Nature 445: 874-880.

5. Rheinwald JG, Green H (1977) Epidermal growth factor and the multiplication of cultured human epidermal keratinocytes. Nature 265: 421-424.

6. Rheinwald JG, Green H (1975) Serial cultivation of strains of human epidermal keratinocytes: the formation of keratinizing colonies from single cells. Cell 6: 331-343.

7. Lanza R, Langer R, Vacanti JP (2011) Principles of tissue engineering Academic press

8. Siedler S,Schuller-Petrovic S (2000)Allogenic keratinocytes suspended in human fibrin glue used for wound healing support in chronic leg ulcers. Archives of dermatology. 136: 676.
9. Nemes Z, Steinert PM (1999) Bricks and mortar of the epidermal barrier. ExpMol Med 31: 5-19.

10. Clark RA, Ghosh K, Tonnesen MG (2007) Tissue engineering for cutaneous wounds. J Invest Dermatol 127: 1018-1029.

11. Hernon CA, Harrison CA, Thornton DJ, MacNeil S (2007) Enhancement of keratinocyte performance in the production of tissue-engineered skin using a low-calcium medium. Wound Repair Regen 15: 718-726.

12. Haddow DB, Steele DA, Short RD, Dawson RA, Macneil S (2003) Plasma-polymerized surfaces for culture of human keratinocytes and transfer of cells to an in vitro wound-bed model. J Biomed Mater Res A 64: 80-87.

13. Moustafa M, Simpson C, Glover M, Dawson RA, Tesfaye S, et al. (2004) A new autologous keratinocyte dressing treatment for non-healing diabetic neuropathic foot ulcers. Diabet Med 21: 786-789.

14. Zhu N,Wraner RM, Simpson C, Glover M, Hernon CA, et al. (2005) Treatment of burns and chronic wounds using a new cell transfer dressing for delivery of autologous keratinocytes. European Journal of Plastic Surgery 28: 319-330.

15. Ronfard V, Broly H, Mitchell V, Galizia JP, Hochart D, et al. (1991) Use of human keratinocytes cultured on fibrin glue in the treatment of burn wounds. Burns 17: 181-184.

16. Rouabhia M, Germain L, Bergeron J, Auger FA (1994) Successful transplantation of chimeric allogeneic-autologous cultured epithelium. Transplant Proc 26: 3361-3362.

17. Rasmussen CA, Gibson AL, Schlosser SJ, Schurr MJ, Allen-Hoffmann BL (2010) Chimeric composite skin substitutes for delivery of autologous keratinocytes to promote tissue regeneration. Ann Surg 251: 368-376.

18. McHeik JN, Barrault C, Bernard FX, Levard G (2010) Quantitative and qualitative study in keratinocytes from foreskin in children: Perspective application in paediatric burns. Burns 36: 1277-1282.

19. De Corte P, Verween G, Verbeken G, Rose T, Jennes S, et al. (2012) Feeder layer-and animal product-free culture of neonatal foreskin keratinocytes: improved performance, usability, quality and safety. Cell and tissue banking13: 175-189.

20. Bikle DD, Xie Z, Tu CL (2012) Calcium regulation of keratinocyte differentiation. Expert Rev EndocrinolMetab 7: 461-472.

21. Griffiths M, Ojeh N, Livingstone R, Price R, Navsaria H (2004) Survival of Apligraf in acute human wounds. Tissue Eng 10: 1180-1195.

22. Bikle DD, Ng D, Tu CL, Oda Y, Xie Z (2001) Calcium- and vitamin Dregulated keratinocyte differentiation. Mol Cell Endocrinol 177: 161-171.

23. Mitev V, Miteva L (1999) Signal transduction in keratinocytes. ExpDermatol 8: 96-108.

24. Denning MF, Dlugosz AA, Williams EK, Szallasi Z, Blumberg PM, et al. (1995) Specific protein kinase C isozymes mediate the induction of keratinocyte differentiation markers by calcium. Cell Growth Differ 6: 149-158.

25. DottoGP (1999) Signal transduction pathways controlling the switch between keratinocyte growth and differentiation. Crit Rev Oral Bio Med 10: 442-457.

26. Freedberg IM, Tomic-Canic M, Komine M, Blumenberg M (2001) Keratins and the keratinocyte activation cycle. J Invest Dermatol 116: 633-640.

27. Wang Y, Wang G, Luo X, Qiu J, Tang C (2012) Substrate stiffness regulates the proliferation, migration, and differentiation of epidermal cells. Burns 38: 414-420.

28. Rosdy M,Clauss LC (1990) Terminal epidermal differentiation of human keratinocytes grown in chemically defined medium on inert filter substrates at the air-liquid interface. Journal of Investigative Dermatology 95: 409-414.

29. Gauvin R,Larouche D, Marcoux H, Guignard R, Auger FA, et al. (2013) Minimal contraction for tissue-engineered skin substitutes when matured at the air-liquid interface. J Tissue EngRegMed7: 452-460.

30. Slominski A, Tobin DJ, Shibahara S, Wortsman J (2004) Melanin pigmentation in mammalian skin and its hormonal regulation. Physiol Rev 84: 1155-1228. 
31. Yamaguchi Y, Brenner M, Hearing VJ (2007) The regulation of skin pigmentation. J BiolChem 282: 27557-27561.

32. Swope VB, Supp AP, Boyce ST (2002) Regulation of cutaneous pigmentation by titration of human melanocytes in cultured skin substitutes grafted to athymic mice. Wound Repair Regen 10: 378-386.

33. Hedley SJ, Layton C, Heaton M, Chakrabarty KH, Dawson RA, et al. (2002) Fibroblasts play a regulatory role in the control of pigmentation in reconstructed human skin from skin types I and II. Pigment Cell Res 15: 49-56.

34. Smola H, Stark HJ, Thiekötter G, Mirancea N, Krieg T, et al. (1998) Dynamics of basement membrane formation by keratinocyte-fibroblast interactions in organotypic skin culture. Exp Cell Res 239: 399-410.

35. Costin GE, Hearing VJ (2007) Human skin pigmentation: melanocytes modulate skin color in response to stress. FASEB J 21: 976-994.

36. Compton CC, Warland G, Kratz G (1998) Melanocytes in cultured epithelial grafts are depleted with serial subcultivation and cryopreservation: implications for clinical outcome. J Burn Care Rehabil 19: 330-336.

37. Liu F, Luo XS, Shen HY, Dong JS, Yang J, et al. (2011) Using human hair follicle-derived keratinocytes and melanocytes for constructing pigmented tissue-engineered skin. Skin Res Technol 17: 373-379.

38. Jeon S, Kim NH, Koo BS, Lee HJ, Lee AY (2005) Bee venom stimulates human melanocyte proliferation, melanogenesis, dendricity and migration. ExpMolMed 39: 603-613.

39. Fang D, Leishear K, Nguyen TK, Finko R, Cai K, et al. (2006) Defining the conditions for the generation of melanocytes from human embryonic stem cells. Stem Cells 24: 1668-1677.

40. Ohta S, Imaizumi Y, Okada Y, Akamatsu W, Kuwahara R, et al. (2011) Generation of human melanocytes from induced pluripotent stem cells. PLoS One 6: e16182.

41. Li L, Fukunaga-Kalabis M, Yu H, Xu X, Kong J, et al. (2010) Human dermal stem cells differentiate into functional epidermal melanocytes. J Cell Sci 123: 853-860.

42. Nishimura EK (2011) Melanocyte stem cells: a melanocyte reservoir in hair follicles for hair and skin pigmentation. Pigment Cell Melanoma Res 24: 401-410.

43. Knight A (2008) Systematic reviews of animal experiments demonstrate poor contributions toward human healthcare. Rev Recent Clin Trials 3: $89-96$.

44. Liu Y, Suwa F, Wang X, Takemura A, Fang YR, et al. (2007) Reconstruction of a tissue-engineered skin containing melanocytes. Cell BiolInt 31: 985-990.

45. Cario-André M, Pain C, Gauthier Y, Casoli V, Taieb A (2006) In vivo and in vitro evidence of dermal fibroblasts influence on human epidermal pigmentation. Pigment Cell Res 19: 434-442.

46. Bottcher-Haberzeth S, Klar AS, Biedermann T, Schiestl C, Meuli-Simmen C, et al. (2013) "Trooping the color": restoring the original donor skin color by addition of melanocytes to bioengineered skin analogs. Pediatric surgery international 29: 239-247.

47. Supp DM, Boyce ST (2005) Engineered skin substitutes: practices and potentials. ClinDermatol 23: 403-412.

48. Sorrell JM, Caplan AI (2004) Fibroblast heterogeneity: more than skin deep. J Cell Sci 117: 667-675.

49. Varkey M, Ding J, Tredget EE (2011) Differential collagen glycosaminoglycan matrix remodeling by superficial and deep dermal fibroblasts: Potential therapeutic targets for hypertrophic scar Biomaterials32: 7581-7591.

50. Varkey M, Ding J, Tredget EE (2013) Superficial Dermal Fibroblasts Enhance Basement Membrane and Epidermal Barrier Formation in Tissue-Engineered Skin: Implications for Treatment of Skin Basement Membrane Disorders. Tissue Eng Part A 20: 540-552.

51. Ghosh K, Pan Z, Guan E, Ge S, Liu Y, et al. (2007) Cell adaptation to a physiologically relevant ECM mimic with different viscoelastic properties. Biomaterials 28: 671-679.
52. Wang LS, Chung JE, Kurisawa M (2012) Controlling fibroblast proliferation with dimensionality-specific response by stiffness of injectable gelatin hydrogels. J BiomaterSciPolym Ed23: 1793-1806.

53. Grinnell F (2003) Fibroblast biology in three-dimensional collagen matrices. Trends Cell Biol 13: 264-269.

54. Rhee S, Grinnell F (2007) Fibroblast mechanics in 3D collagen matrices. Adv Drug Deliv Rev 59: 1299-1305.

55. Wong T, McGrath JA, Navsaria $\mathrm{H}$ (2007) The role of fibroblasts in tissue engineering and regeneration. Br J Dermatol 156: 1149-1155.

56. Campoccia D, Doherty P, Radice M, Brun P, Abatangelo G, et al. (1998) Semisynthetic resorbable materials from hyaluronan esterification. Biomaterials 19: 2101-2127.

57. Caravaggi C, De Giglio R, Pritelli C, Sommaria M, DallaNoce S, et al. (2003) HYAFF 11-Based Autologous Dermal and Epidermal Grafts in the Treatment of Noninfected Diabetic Plantar and Dorsal Foot Ulcers A prospective, multicenter, controlled, randomized clinical trial. Diabetes Care26: 2853-2859.

58. Uccioli L (2013) A clinical investigation on the characteristics and outcomes of treating chronic lower extremity wounds using the tissuetech autograft system. IntJLow ExtremWounds2: 140-151.

59. Nomi M, Atala A, Coppi PD, Soker S (2002) Principals of neovascularization for tissue engineering. Mol Aspects Med 23: 463-483.

60. Eppler SM, Combs DL, Henry TD, Lopez JJ, Ellis SG, et al. (2002) A target-mediated model to describe the pharmacokinetics and hemodynamic effects of recombinant human vascular endothelial growth factor in humans. ClinPharmacolTher72: 20-32.

61. Phillips TJ (1998) New skin for old: developments in biological skin substitutes. Arch Dermatol 134: 344-349.

62. Schneider EL, Mitsui Y (1976) The relationship between in vitro cellular aging and in vivo human age. ProcNatlAcadSci U S A 73: 3584-3588.

63. Lamme EN, van Leeuwen RT, Mekkes JR, Middelkoop E (2002) Allogeneic fibroblasts in dermal substitutes induce inflammation and scar formation. Wound Repair Regen 10: 152-160.

64. Morimoto N, Saso Y, Tomihata K, Taira T, Takahashi Y, et al. (2005) Viability and function of autologous and allogeneic fibroblasts seeded in dermal substitutes after implantation. J Surg Res 125: 56-67.

65. Werner S, Krieg T, Smola H (2007) Keratinocyte-fibroblast interactions in wound healing. J Invest Dermatol 127: 998-1008.

66. Florin L, Maas-Szabowski N, Werner S, Szabowski A, Angel P (2005) Increased keratinocyte proliferation by JUN-dependent expression of PTN and SDF-1 in fibroblasts. J Cell Sci 118: 1981-1989.

67. Yamaguchi Y, Passeron T, Watabe H, Yasumoto K, Rouzaud F, et al. (2007) The effects of dickkopf 1 on gene expression and Wnt signaling by melanocytes: mechanisms underlying its suppression of melanocyte function and proliferation. J Invest Dermatol 127: 1217-1225.

68. Atiyeh BS, Costagliola M (2007) Cultured epithelial autograft (CEA) in burn treatment: three decades later. Burns 33: 405-413.

69. Haddow DB, France RM, Short RD, MacNeil S, Dawson RA, et al. (1999) Comparison of proliferation and growth of human keratinocytes on plasma copolymers of acrylic acid/1,7-octadiene and self-assembled monolayers. J Biomed Mater Res 47: 379-387.

70. Ronfard V, Broly H, Mitchell V, Galizia JP, Hochart D, et al. (1991) Use of human keratinocytes cultured on fibrin glue in the treatment of burn wounds. Burns 17: 181-184.

71. Currie LJ, Sharpe JR, Martin R (2001) The use of fibrin glue in skin grafts and tissue-engineered skin replacements: a review. PlastReconstrSurg 108: 1713-1726.

72. Harris PA, Leigh IM, Navsaria HA (1998) Pre-confluent keratinocyte grafting: the future for cultured skin replacements? Burns 24: 591-593.

73. Schultz GS, Sibbald RG, Falanga V, Ayello EA, Dowsett C, et al. (2003) Wound bed preparation: a systematic approach to wound management. Wound Repair Regen 11 Suppl 1: S1-28.

74. Marston WA, Hanft J, Norwood P, Pollak R; Dermagraft Diabetic Foot Ulcer Study Group (2003) The efficacy and safety of Dermagraft in 
improving the healing of chronic diabetic foot ulcers: results of a prospective randomized trial. Diabetes Care 26: 1701-1705.

75. Gravante G, Delogu D, Giordan N, Morano G, Montone A, et al. (2007) The use of Hyalomatrix PA in the treatment of deep partial-thickness burns. J Burn Care Res 28: 269-274.

76. Cervelli V, Lucarini L, Cerretani C, Spallone D, Palla L, et al. (2010) The use of Matriderm and autologous skin grafting in the treatment of diabetic ulcers: a case report. Int Wound J 7: 291-296.

77. Mostow EN, Haraway GD, Dalsing M, Hodde JP, King D; OASIS Venus Ulcer Study Group (2005) Effectiveness of an extracellular matrix graft (OASIS Wound Matrix) in the treatment of chronic leg ulcers: a randomized clinical trial. J VascSurg 41: 837-843.

78. Suzuki S, Kawai K, Ashoori F, Morimoto N, Nishimura Y, et al. (2000) Long-term follow-up study of artificial dermis composed of outer silicone layer and inner collagen sponge. Br J PlastSurg 53: 659-666.

79. Mansbridge J (2006) Commercial considerations in tissue engineering. J Anat 209: 527-532.

80. Nolte SV, Xu W, Rennekampff HO, Rodemann HP (2008) Diversity of fibroblasts--a review on implications for skin tissue engineering. Cells Tissues Organs 187: 165-176.

81. Sabolinski ML, Alvarez O, Auletta M, Mulder G, Parenteau NL (1996) Cultured skin as a 'smart material' for healing wounds: experience in venous ulcers. Biomaterials 17: 311-320.

82. Still J, Glat P, Silverstein P, Griswold J, Mozingo D (2003) The use of a collagen sponge/living cell composite material to treat donor sites in burn patients. Burns 29: 837-841.

83. Boyce ST,Kagan RJ, Greenhalgh DG, Warner P, Yakuboff KP, et al. (2006) Cultured skin substitutes reduce requirements for harvesting of skin autograft for closure of excised, full-thickness burns. J Trauma 60: 821-829.

84. Edmonds M; European and Australian Apligraf Diabetic Foot Ulcer Study Group (2009) Apligraf in the treatment of neuropathic diabetic foot ulcers. Int J Low Extrem Wounds 8: 11-18.

85. Sahota PS, Burn JL, Heaton M, Freedlander E, Suvarna SK, et al. (2003) Development of a reconstructed human skin model for angiogenesis. Wound Repair Regen 11: 275-284.

86. Jain RK, Au P, Tam J, Duda DG, Fukumura D (2005) Engineering vascularized tissue. Nat Biotechnol 23: 821-823.

87. Blinder Y, Mooney D, Levenberg S (2014) Engineering approaches for inducing blood vessel formation. Current Opinion in Chemical Engineering 3: 56-61.

88. Hendrickx B, Vranckx JJ, Luttun A (2011) Cell-based vascularization strategies for skin tissue engineering. Tissue Eng Part B Rev 17: 13-24.

89. Ahmed TA, Dare EV, Hincke M (2008) Fibrin: a versatile scaffold for tissue engineering applications. Tissue Eng Part B Rev 14: 199-215.

90. Galeano M,Polito F, Bitto A, Irrera N, Campo GM, et al. (2011) Systemic administration of high-molecular weight hyaluronan stimulates wound healing in genetically diabetic mice. BiochimicaBiophysActa 1812: 752-759.

91. Lee W, Lee V, Polio S, Keegan P, Lee JH, et al. (2010) On-demand threedimensional freeform fabrication of multi-layered hydrogel scaffold with fluidic channels. BiotechnolBioeng 105: 1178-1186.

92. Tremblay PL, Hudon V, Berthod F, Germain L, Auger FA (2005) Inosculation of tissue-engineered capillaries with the host's vasculature in a reconstructed skin transplanted on mice. Am J Transplant 5: 1002-1010.

93. Novosel EC, Kleinhans C, Kluger PJ (2011) Vascularization is the key challenge in tissue engineering. Adv Drug Deliv Rev 63: 300-311.

94. Lovett M, Lee K, Edwards A, Kaplan DL (2009) Vascularization strategies for tissue engineering. Tissue Eng Part B Rev 15: 353-370.

95. Cervelli V, De Angelis B, Balzani A, Colicchia G, Spallone D, et al. (2009) Treatment of stable vitiligo by ReCell system. ActaDermatovenerol Croat 17: 273-278.
96. Mulekar SV, Ghwish B, Al Issa A, Al Eisa A (2008) Treatment of vitiligo lesions by ReCell vs. conventional melanocyte-keratinocyte transplantation: a pilot study. Br J Dermatol 158: 45-49.

97. Wu Y, Chen L, Scott PG, Tredget EE (2007) Mesenchymal stem cells enhance wound healing through differentiation and angiogenesis. Stem Cells 25: 2648-2659.

98. Falanga V, Iwamoto S, Chartier M, Yufit T, Butmarc J, et al. (2007) Autologous bone marrow-derived cultured mesenchymal stem cells delivered in a fibrin spray accelerate healing in murine and human cutaneous wounds. Tissue Eng 13: 1299-1312.

99. Chan RK, Zamora DO, Wrice NL, Baer DG, Renz EM, et al. (2012) Development of a vascularized skin construct using adipose-derived stem cells from debrided burned skin. Stem Cells Int 2012: 841203.

100. Kim WS, Park BS, Sung JH, Yang JM, Park SB, et al. (2007) Wound healing effect of adipose-derived stem cells: a critical role of secretory factors on human dermal fibroblasts. J DermatolSci 48: 15-24.

101. Sasaki M, Abe R, Fujita Y, Ando S, Inokuma D, et al. (2008) Mesenchymal stem cells are recruited into wounded skin and contribute to wound repair by transdifferentiation into multiple skin cell type. J Immunol 180: 2581-2587.

102. Li H, Fu X, Ouyang Y, Cai C, Wang J, et al. (2006) Adult bone-marrowderived mesenchymal stem cells contribute to wound healing of skin appendages. Cell Tissue Res 326: 725-736.

103. Mansilla E, Marin GH, Sturla F, Drago HE, Gil MA, et al. (2005) Human mesenchymal stem cells are tolerized by mice and improve skin and spinal cord injuries. Transplant Proc 37: 292-294.

104. Gimble J,Guilak F (2003) Adipose-derived adult stem cells: isolation, characterization, and differentiation potential. Cytotherapy5: 362-369.

105. Kern S, Eichler H, Stoeve J, Klüter H, Bieback K (2006) Comparative analysis of mesenchymal stem cells from bone marrow, umbilical cord blood, or adipose tissue. Stem Cells 24: 1294-1301.

106. Lin K, Matsubara Y, Masuda Y, Togashi K, Ohno T, et al. (2008) Characterization of adipose tissue-derived cells isolated with the Celution system. Cytotherapy 10: 417-426.

107. Lee EY, Xia Y, Kim WS, Kim MH, Kim TH, et al. (2009) Hypoxiaenhanced wound-healing function of adipose-derived stem cells: increase in stem cell proliferation and up-regulation of VEGF and bFGF. Wound Repair Regen 17: 540-547.

108. Nie C, Yang D, Xu J, Si Z, Jin X, et al. (2011) Locally administered adipose-derived stem cells accelerate wound healing through differentiation and vasculogenesis. Cell Transplant 20: 205-216.

109. Lin YC, Grahovac T, Oh SJ, Ieraci M, Rubin JP, et al. (2013) Evaluation of a multi-layer adipose-derived stem cell sheet in a full-thickness wound healing model. ActaBiomater 9: 5243-5250.

110. Trottier V, Marceau-Fortier G, Germain L, Vincent C, Fradette J (2008) IFATS collection: Using human adipose-derived stem/stromal cells for the production of new skin substitutes. Stem Cells 26: 2713-2723.

111. Hoffman RM (2007) The potential of nestin-expressing hair follicle stem cells in regenerative medicine. Expert OpinBiolTher 7: 289-291.

112. Toma JG, McKenzie IA, Bagli D, Miller FD (2005) Isolation and characterization of multipotent skin-derived precursors from human skin. Stem Cells 23: 727-737.

113. Kruse C, Bodó E, Petschnik AE, Danner S, Tiede S, et al. (2006) Towards the development of a pragmatic technique for isolating and differentiating nestin-positive cells from human scalp skin into neuronal and glial cell populations: generating neurons from human skin? ExpDermatol 15: 794-800.

114. Petschnik AE, Klatte JE, Evers LH, Kruse C, Paus R, et al. (2010) Phenotypic indications that human sweat glands are a rich source of nestin-positive stem cell populations. Br J Dermatol162: 380-383.

115. Nagel S, Rohr F, Weber C, Kier J, Siemers F, et al. (2013)MultipotentNestin-Positive Stem Cells Reside in the Stroma of Human Eccrine and Apocrine Sweat Glands and Can Be Propagated Robustly In Vitro. PloS one 8: e78365. 
116. Amoh Y, Li L, Yang M, Moossa AR, Katsuoka K, et al. (2004) Nascent blood vessels in the skin arise from nestin-expressing hair-follicle cells. ProcNatlAcadSci U S A 101: 13291-13295.

117. Aki R,Amoh Y, Li L, Katsuoka K, Hoffman RM, et al. (2010)Nestinexpressing interfollicular blood vessel network contributes to skin transplant survival and wound healing. J Cell Biochem 110: 80-86.

118. Danner S, Kremer M, Petschnik AE, Nagel S, Zhang Z, et al. (2012) The use of human sweat gland-derived stem cells for enhancing vascularization during dermal regeneration. J Invest Dermatol 132 1707-1716.

119. Pappa KI, Anagnou NP (2009) Novel sources of fetal stem cells: where do they fit on the developmental continuum? Regen Med 4: 423-433.

120. De Coppi P, Bartsch G Jr, Siddiqui MM, Xu T, Santos CC, et al. (2007) Isolation of amniotic stem cell lines with potential for therapy. Nat Biotechnol 25: 100-106.

121. Kolambkar YM, Peister A, Soker S, Atala A, Guldberg RE (2007) Chondrogenic differentiation of amniotic fluid-derived stem cells. J MolHistol 38: 405-413.
122. Moorefield EC, McKee EE, Solchaga L, Orlando G, Yoo JJ, et al. (2011) Cloned, CD117 selected human amniotic fluid stem cells are capable of modulating the immune response. PLoS One 6: e26535.

123. Yoon BS, Moon JH, Jun EK, Kim J, Maeng I, et al. (2010) Secretory profiles and wound healing effects of human amniotic fluid-derived mesenchymal stem cells. Stem Cells Dev 19: 887-902.

124. Hartmann-Fritsch F, Hosper N, Luginbühl J, Biedermann T, Reichmann E, et al. (2013) Human amniotic fluid derived cells can competently substitute dermal fibroblasts in a tissue-engineered dermo-epidermal skin analog. Pediatric surgery international 29: 61-69.

125. Skardal A, Mack D, Kapetanovic E, Atala A, Jackson JD, et al. (2012) Bioprinted amniotic fluid-derived stem cells accelerate healing of large skin wounds. Stem Cells Transl Med 1: 792-802. 